\title{
2007s-01
}

\section{Ambiguity Aversion as a Predictor of Technology Choice: \\ Experimental Evidence from Peru}

\author{
Jim Engle-Warnick, Javier Escobal, \\ Sonia Laszlo
}

\begin{tabular}{c}
\hline Série Scientifique \\
Scientific Series
\end{tabular}

\section{Montréal}

Janvier 2007

(C) 2007 Jim Engle-Warnick, Javier Escobal, Sonia Laszlo. Tous droits réservés. All rights reserved.
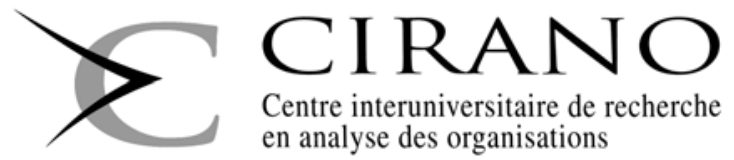

Centre interuniversitaire de recherche en analyse des organisations 


\section{CIRANO}

Le CIRANO est un organisme sans but lucratif constitué en vertu de la Loi des compagnies du Québec. Le financement de son infrastructure et de ses activités de recherche provient des cotisations de ses organisations-membres, d'une subvention d'infrastructure du Ministère du Développement économique et régional et de la Recherche, de même que des subventions et mandats obtenus par ses équipes de recherche.

CIRANO is a private non-profit organization incorporated under the Québec Companies Act. Its infrastructure and research activities are funded through fees paid by member organizations, an infrastructure grant from the Ministère du Développement économique et régional et de la Recherche, and grants and research mandates obtained by its research teams.

\section{Les partenaires du CIRANO}

Partenaire majeur

Ministère du Développement économique, de l'Innovation et de l'Exportation

\section{Partenaires corporatifs}

\section{Alcan inc.}

Banque de développement du Canada

Banque du Canada

Banque Laurentienne du Canada

Banque Nationale du Canada

Banque Royale du Canada

Banque Scotia

Bell Canada

BMO Groupe financier

Bourse de Montréal

Caisse de dépôt et placement du Québec

DMR Conseil

Fédération des caisses Desjardins du Québec

Gaz de France

Gaz Métro

Hydro-Québec

Industrie Canada

Investissements PSP

Ministère des Finances du Québec

Raymond Chabot Grant Thornton

State Street Global Advisors

Transat A.T.

Ville de Montréal

\section{Partenaires universitaires}

École Polytechnique de Montréal

HEC Montréal

McGill University

Université Concordia

Université de Montréal

Université de Sherbrooke

Université du Québec

Université du Québec à Montréal

Université Laval

Le CIRANO collabore avec de nombreux centres et chaires de recherche universitaires dont on peut consulter la liste sur son site web.

Les cahiers de la série scientifique (CS) visent à rendre accessibles des résultats de recherche effectuée au CIRANO afin de susciter échanges et commentaires. Ces cahiers sont écrits dans le style des publications scientifiques. Les idées et les opinions émises sont sous l'unique responsabilité des auteurs et ne représentent pas nécessairement les positions du CIRANO ou de ses partenaires.

This paper presents research carried out at CIRANO and aims at encouraging discussion and comment. The observations and viewpoints expressed are the sole responsibility of the authors. They do not necessarily represent positions of CIRANO or its partners. 


\title{
Ambiguity Aversion as a Predictor of Technology Choice: Experimental Evidence from Peru
}

\author{
Jim Engle-Warnick ${ }^{\dagger}$, Javier Escobal ${ }^{\ddagger}$, Sonia Laszlo ${ }^{\S}$
}

\begin{abstract}
Résumé / Abstract
Un phénomène bien documenté en économie du développement est le nombre peu élevé d'agriculteurs qui décident d'adopter de nouvelles technologies en agriculture, malgré leurs avantages connus. En plus des nombreuses contraintes imposées par le marché, l'aversion au risque prédomine la discussion sur les déterminants de l'adoption de nouvelles technologies. Nous émettons l'hypothèse que l'aversion à l'ambiguïté pourrait aussi être un déterminant puisqu'il est possible que les agriculteurs aient moins d'information sur la distribution du rendement des nouvelles technologies que sur celle des technologies traditionnelles. Nous testons la validité de cette hypothèse avec une expérience en laboratoire sur le terrain où nous mesurons les préférences vis-à-vis du risque et de l'ambiguïté. Nous combinons notre expérience à un sondage portant sur les décisions prises en matière d'agriculture et identifiant les contraintes du marché. Nous constatons qu'effectivement, l'aversion à l'ambiguïté dicte les choix technologiques réels relatifs à la ferme.
\end{abstract}

Mots clés : choix technologiques, développement rural, économie expérimentale, instruments de mesure du risque, préférences vis-à-vis du risque

The lack of adoption of new farming technologies despite known benefis is a well-documented phenomenon in development economics. In addition to a number of market constraints, risk aversion predominates the discussion of behavioral determinants of technology adoption. We hypothesize that ambiguity aversion may also be a determinant, since farmers may have less information about the distribution of yield outcomes from new technologies compared with traditional technologies. We test this hypothesis with a laboratory experiment in the field in which we measure risk and ambiguity preferences. We combine our experiment with a survey in which we collect information on farm decisions and identify market constraints. We find that ambiguity aversion does indeed predict actual technology choices on the farm.

Keywords: experimental economics, risk measurement instruments, risk preferences, rural development, technology choice

Codes JEL : O33, O18, C91

\footnotetext{
${ }^{*}$ We thank Cathleen Johnson, Claude Montmarquette, and seminar and conference participants at McGill University, the 2006 NEUDC and Tucson ESA meetings. We thank Duncan Whitehead and Rafael Novella for research assistance, as well as our field surveyors Luis Suarez, Francisco Barrios and Fernando Manrique. We gratefully acknowledge the Social Science and Humanities Research Council of Canada as well as the Association of Universities and Colleges of Canada for funding, and the Centre for Interuniversity Research and Analysis on Organizations (CIRANO) and the Bell University Laboratory in Electronic Commerce and Experimental Economy for use of the experimental laboratory.

${ }^{\dagger}$ Department of Economics, McGill University and CIRANO, Montreal, Quebec.

‡ Group for the Analysis of Development.

§ Department of Economics, 855 Sherbrooke St. W., McGill University, Montreal, QC, H3A 2T7, Canada, e-mail: sonia.laszlo@mcgill.ca, tel.: (514) 398-1924; fax: (514) 398-4938.
} 


\section{Introduction}

The adoption of new technologies among subsistence farmers in developing countries is a predominant issue in policy and academic debates in economic development, and has been receiving an increasing amount of attention in recent years. Farmers make decisions regarding new technology adoption, for equipment, for seeds, and possibly for transport. Yet development economists have often observed a lack of innovation in farming, which some authors have linked to the persistence of rural poverty in developing countries. Understanding how farmers make decisions would help in understanding why they do or do not adopt new technology. The difficulty is that many factors affecting the decision process are not observable to outsiders. For example, individual preferences toward risk and ambiguity are typically not known and some individual decisions might appear to not square well with models of rationality.

This study is the first to attempt to distinguish empirically between risk aversion and ambiguity aversion in farmers' technology choices in developing countries. It combines a new survey with new data using behavioral tests developed from economics experiments to dig deeper into farmers' decision processes in adopting new technology in rural Peru. Our study differs methodologically from others in that it contains both a laboratory experiment in the field and a socioeconomic survey, and it includes both risk and ambiguity preference measures.

In the experiment we measure farmers' predispositions toward risk, toward ambiguity, and toward making individual choices that do not fit the model of rationality. In the survey we collect information about households and farming choices. We use the experiment to provide additional variables to explain the choice of technology use on the farms.

We make two main contributions. First, we find evidence of a correlation between ambiguity aversion, but not risk aversion, and technology choice. This finding contrasts with the long-held notion that risk aversion prevents the adoption of new technology. Our finding 
is complementary to others who compare preferences with decision making in developing countries (see Feder, Just and Zilberman (1985) and Knight, Weir and Woldehanna (2003)). In addition, like Duflo, Kremer, and Robinson (2006), who present an experimental design that reveals a time inconsistency feature of farmers' choices to buy fertilizer, we explore features of farmers' preferences that do not appear to be rational in the traditional sense of economic theory, and that affect their choices. Our approach differs from theirs because it is a laboratory study, not an intervention: we measure preferences in a field laboratory and then correlate our measures with survey data on technology choices. A goal of our approach is to guide future interventions.

Second, we contribute to the literature on using incentive-compatible instruments to explain and predict behavior. This literature takes two main tacks. First, many researchers now use risk and time preferences to help explain real-life decisions (e.g., see the laboratory experiments combined with the Mexican Family Life Survey in Eckel, Hotz, Johnson, Rubalcava, Teruel, Thomas, Conroy, and Hamoudi, (2006)). Second, research is being conducted to determine more precisely what the instruments measure (e.g., Eckel, Engle-Warnick, and Johnson (2005)). Our study and field work advances knowledge regarding the instruments by searching for correlations between the laboratory decisions and real-life decisions with the same subject.

\section{Technology Choice}

To illustrate a technology choice, imagine that a farmer has been growing a traditional variety of a particular crop, say potato. In the case of Peru, this might be a variety that her family has been planting for generations, possibly dating back to Inca times. This traditional variety of potato might have a low expected yield, but the farmer knows reasonably well how much it will yield in a good year and how much it will yield in a bad year. Furthermore, even in a bad 
year, this particular variety will yield enough potatoes to make it likely that she will be able to feed her family. New and modern varieties of potato appear from time to time, however, such as the Papa Capiro, that perform reasonably well in the farmer's region, and has shown to provide substantial yield improvements at relatively low cost (e.g. technical know-how) of adoption. In fact, there might even be a number of non-profit technical assistance programs in the area to bring such costs of adoption to a strict minimum. Yet, it is still possible that this farmer will continue to choose to grow the traditional variety.

It is a well established fact that, despite presumed yield improvements, farmers in developing countries do not always adopt new technologies, whether these are high yielding varieties (HYV) or modern complementary inputs such as chemical fertilizers. The literature has put forward several possible hypotheses for what might determine a farmer's propensity to adopt. Among the many hypotheses, one that stands out is that subsistence farmers do not adopt new technologies because they are risk averse. Since subsistence farmers are typically poor, they prefer not to undertake risky projects: they are not willing to take the chance, however remote, that the new technology will not meet the minimum yield to ensure a subsistence existence.

Suppose that the farmer must choose between a traditional, but safe, technology and a modern one with potentially high expected yield. The modern technology may have a larger yield variance, or perhaps she might perceive it this way. She will view the new technology to be riskier. Poor individuals might have a stronger aversion towards risky technologies because they are poor. Put another way, poor farmers are more averse than rich farmers to the probability that the new technology will have a low yield, because in a bad year the poor farmer may fall below subsistence. Therefore, we would expect that technology adoption is less likely among relatively risk averse farmers. Several influential studies have documented the important role that farmers' risk preferences has on the adoption of new farming technologies (Feder, 1980; Feder, Just and Zilberman, 1985; Antle and Crissman, 
1990; Knight, Weir and Woldehanna, 2003).

Hypothesis 1 (Risk preferences) Technology adoption is decreasing in risk aversion.

The effect of risk preferences on technology adoption addresses one form of uncertainty the farmer knows (or has subjective beliefs about) the distribution of outcomes, but does not know the realization of the outcome until it occurs. However, it is possible that the farmer simply does not know the distribution of outcomes. In other words, the farmer does not know the probability of high and low yields with the modern technology. This second type of uncertainty, known as Knightian uncertainty (Knight, 1921), implies that ambiguity aversion may matter in the choice of technologies. It pertains to the aversion towards the uncertainty about the probability distribution over outcomes. The technology choice problem can be expressed quite appropriately in the context of ambiguity: traditional farming technologies tend to have known yield distributions, whereas modern farming technologies tend to have unknown yield distributions (at least to the farmer who is deciding which technology to choose). Therefore, in addition to risk aversion, one might expect ambiguity aversion to be at least equally important in determining which technology to choose.

Hypothesis 2 (Ambiguity preferences) Technology adoption is decreasing in ambiguity aversion.

In thinking about behavioral determinants of technology choice, the literature has mostly focused on the role of the farmers' attitudes towards risk. In this paper, we suggest that due to the ambiguous nature of the yield distribution of modern seed varieties, ambiguity aversion should matter at least as much as risk aversion in determining whether farmers adopt new technologies. To the best of our knowledge, this paper is the first to attempt to empirically distinguish between risk and ambiguity aversion's effect on technology choice among farmers in developing countries. ${ }^{1}$

\footnotetext{
${ }^{1}$ For a recent theoretical discussion of the relationship between ambiguity aversion and innovation, see Rigotti, Ryan and Vaithianathan (2003).
} 
Neoclassical approaches to decision-making among the poor assume among other things that agents are rational. However, there is growing evidence that this is not a universal rule among the poor and several papers have documented important examples where the assumption of bounded rationality has failed (e.g. the time inconsistency problem noted by Duflo et al. (2006)). For example, in a previous study where subsistence farmers in the Peruvian Costa were given the task to choose among different lotteries, we found that farmers revealed a non-negligible preference for payoff dominated gambles (Engle-Warnick, Escobal and Laszlo, 2006). The effect of non-rational choice on technology adoption should work against profit maximization. Thus if we assume that adoption of new technology is profitable, we would expect people who exhibit this type of behavior to be slow to adopt.

Hypothesis 3 (Non-rational behavior) Technology adoption is decreasing in non-rational behavior.

It is also important to mention other, non-behavioral, hypotheses that shed light on the lack of technology adoption among farmers in developing countries. First, poverty (or inversely wealth) may slow or prevent technology adoption. Poor farmers who are liquidity constrained are not able to undertake the investment into the new alternative because they are unable to cover the cost of the investment (purchase of the new seeds or fertilizers). Second, in an environment with perfect credit markets, poverty should not prevent the investment because the farmer would be able to borrow against future crop yield (this argument is made in Besley and Case (1993) and elsewhere). However, if credit markets are imperfect, as they tend to be in most rural areas of developing countries (especially in rural Peru), then farmers face a binding borrowing constraint. In such a scenario, poor farmers who would want to plant the new seed or spread new fertilizer would not be able to do so because they cannot borrow to cover their cost. Duflo et al. (2006) find evidence of liquidity constraints among Kenyan maize farmers. 
Third, learning of various kinds are also important determinants of technology adoption. In particular, Foster and Rosenzweig (1995) and Duflo et al. (2006) find evidence of the effect of learning by doing on adoption in India and Kenya, respectively. ${ }^{2}$ If learning by doing is an important determinant of adoption, then we would expect that more experienced farmers are more likely to choose a new technology. More experienced farmers are more familiar with the how inputs interact. Because the learning models assume that as one uses a technology, one noisily learns about other technologies, past experience with new varieties should also be correlated to a higher propensity to adopt.

Fourth, the recent literature has focused a great deal on the social learning (or learning from others) hypothesis. The idea is simple. Suppose one farmer in the community is willing to undertake the investment into a new technology. Call her the 'leader'. Other farmers in the community may wait to see what happens on her plots before deciding whether they too should undertake this investment. Similarly, they might watch what she is doing and how she is doing it before jumping in themselves. Eventually, they may choose to follow her example and also choose the new technology. They are the 'followers'. In other words, the probability that a farmer will adopt a new seed or a new fertilizer will depend on whether others in her community have also adopted it. However straightforward, identifying empirically this social learning hypothesis is difficult to do because of the reflection problem noted in Manski (1993). The correlation between the adoption by other community members and the farmer's adoption might be driven by a third, perhaps unobserved, factor, thus causing an endogeneity bias. Several studies have nonetheless found convincing approaches to identifying social learning and technology choice among farmers: Foster and Rosenzweig (1995) and Munshi (2004) found evidence of social learning among maize farmers in India, Conley and Udry (2006) among pineapple farmers in Ghana and Duflo et al. (2006) among maize farmers in Kenya.

\footnotetext{
2 See Jovanovic and Nyarko (1996) for the theoretical discussion of learning by doing and technology adoption using a target input model, used in Foster and Rosenzweig (1995).
} 
Hypothesis 4 (Non-behavioral hypotheses) The following summarizes some of the main non-behavioral determinants of technology adoption:

1. Income positively affects a farmer's decision to adopt a new technology. Conversely, poverty will reduce the probability that the farmer adopts.

2. Poor farmers who face a borrowing constraint are less likely to adopt a new technology than farmers who can draw from their own savings or who have access to credit.

3. Learning by doing is an important determinant of technology adoption. More educated and more experienced farmers are thus more likely to adopt a new technology.

4. Farmers are more likely to adopt a new variety if their neighbors have already adopted it themselves.

With these hypotheses in mind, we now turn to the case of Peru, where we visited rural communities in two areas, the Central Costa and Central Sierra. There we ran a socioeconomic survey with questions pertaining to agricultural technology choices, and laboratory experiments in the field to elicit farmers' preferences under uncertainty.

\section{Experimental Design}

Our experimental design consists of measures of risk preferences, measures of ambiguity preferences, and tests for preferences for payoff dominated alternatives as a test of 'irrational' preferences. The design is as simple as we could make it. The goal of our design is to provide a set of explanatory variables that complement those that we generate in our socioeconomic survey, refining our ability to understand technology choice. ${ }^{3}$

\subsection{Risk Preference Measure}

Figure 1 shows the instrument, inspired by Eckel and Grossman (2003) and denoted 'five options' (FO), which we use to derive our preference measure. Our subjects are instructed to select exactly one of the five options. Each option is represented by a circle which contains

\footnotetext{
${ }^{3}$ This design is identical to the one used in Engle-Warnick and Laszlo (2006), where we run the sessions in a traditional laboratory environment.
} 
two payoffs, each with a $50 \%$ probability of occurring. To illustrate, the top option pays 26 Nuevos Soles (S/.) with certainty, while the option to its right has a low payoff of $2 \mathrm{~S} /$. (with $50 \%$ probability) and a high payoff of $62 \mathrm{~S} /$. (with $50 \%$ probability). ${ }^{4}$ The variance in the payoffs increases as we move counter clockwise from the top option.

Our measure of risk preferences, denoted 'risk measure' (RM), is derived by decomposing FO into a set of four binary choices. This decomposition resembles the instrument in Holt and Laury (2000). Figure 2 presents this decomposition. Each row in the figure corresponds to a signle binary choice between two alternative gambles. Specifically, each row depicts a choice between two alternatives that are contiguous in the FO instrument. Beginning with the first row of choices and moving down, an expected utility maximizer will at some point switch from the left-hand side gamble with lower variance to the right-hand side gamble with a higher variance and slightly higher expected utility. The sooner the subject switches from the left-hand side to the right-hand side, the less relatively risk averse she is. ${ }^{5}$

\subsection{Ambiguity Preference Measure}

Our measure of ambiguity preferences, denoted 'ambiguity measure' (AM), is depicted in Figure 3. Figure 3 presents five decisions, one in each row. In the figure, the gamble on the left displays the possible prizes, but not the probability of winning those prizes (this is communicated by eliminating the vertical line in the center of the circle). The gamble on the right contains the same prizes, but with a 50/50 chance of winning each one. However, if a subject chooses the gamble on the right, she must pay $0.50 \mathrm{~S} /$. of her final earnings back to the experimenter for making this choice. ${ }^{6}$ Thus the left gamble is ambiguous in the sense

\footnotetext{
${ }^{4} 10 \mathrm{~S} /$. are equal to approximately $\$ 3$ US.

${ }^{5}$ Our motivation for decomposing FO into RM was to use the relatively simple 50/50 choice gambles within a framework within which we could study the effect of adding additional alternatives to the choice set. The experimental design also consists of a set of questions that study the effect of additional choices. For a description of this aspect of the design, see Engle-Warnick, Escobal, and Laszlo (2006).

${ }^{6}$ In no case can this ever result in a negative payoff for choices in the experiment.
} 
that the subject does not know the probability distribution over outcomes, and the costly right gamble provides the subject with an opportunity to reveal her preference to avoid this ambiguity. $^{7}$

Our measure of ambiguity aversion reflects choices for simplification that we had to make to run our laboratory experiment in Peru. There are at least two other methods we could have used. Perhaps the most standard way to measure ambiguity aversion in the laboratory is to elicit subjects' willingness to pay for the ambiguous gamble and for the unambiguous gamble separately, then take the difference between the two valuations as the measure. This requires using the Becker, Degroot, Marschak (1964) procedure, in which subjects report their valuation of the gamble, then they sell the gamble to the experimenter if a random number comes up larger than their valuation, and play the gamble it if it comes up smaller.

We could also have varied the amount of money it cost to select the unambiguous gamble across the five gambles we used for the measure, taking the minimum amount subjects were willing to pay as our measure. This would have involved either choosing one of the gambles and varying the price each time it was presented, or determining how to vary the price among the five different gambles presented.

We chose our simpler design with multiple gambles and a single price to avoid ambiguity because it avoids the complicated Becker, DeGroot, and Marschak (1964) procedure of elicitation, because it is easy to derive a measure from, and because it enabled our ambiguity test to mirror our risk preference and rationality tests as closely as possible. We believe that it is important to follow up on these different methods to determine if one is a better measure than the others.

\footnotetext{
${ }^{7}$ In this case, as in the Ellsberg Paradox, if the the distribution over possible distributions of outcomes in the ambiguous gamble is uniform, an expected utility maximizer should be indifferent between the two gambles, and should not pay to avoid the ambiguous gamble. Ellsberg (1961) suggested the original experiments which form the basis if literature on ambiguity preferences.
} 


\subsection{Dominated Alternative Preference Measure}

Our third test, which we denote 'dominated choice' (DC) is designed to reveal preferences for payoff-dominated alternatives. This measure can be thought of as a measure of the subjects' ability to understand the decision-making problem, or a measure of a type of subject who for some reason legitimately prefers to leave money on the table, or some other kind of nonrational behavior. Figure 4 shows the five choices subjects faced with a payoff-dominated gamble. Thus for each of the five base gambles, we test whether subjects would prefer a gamble that is dominated in both possible payoffs. ${ }^{8}$

\subsection{Explanatory Variables Generated by the Experiment}

We constructed an explanatory variable for each one of the three behavioral measures in our experiment. Embedded within the decisions our subjects made was a set of choices relevant to each measure. We take those choices and construct three measures.

First, to measure risk preferences, we take the four decisions depicted in Figure 2, noting that each decision is a choice between a relatively safe and a relatively risky gamble. For the risk preference measure we simply count the number of risky choices made by the subject. The fewer risky choices, which can take on integer values from zero to four, the less risk averse a subject is. This measure is equivalent to the one used by Holt and Laury (2002).

Second, to measure ambiguity preferences, precisely as in our measure of risk preferences, we count the number of times subjects pay to avoid an ambiguous gamble in each of the five choice problems shown in Figure 3. This measure takes on integer values from zero to five. For a simple model of decision making, one can think of a subject who has a predisposition against ambiguity. The higher this predisposition, the more likely the subject is to pay to

\footnotetext{
${ }^{8}$ We include these tests based on our findings in Engle-Warnick, Escobal and Laszlo (2006), where subjects chose payoff dominated alternatives $25 \%$ of the time they were available among a set of three alternatives. We wished to discover whether they would directly reveal their preferences for these gambles in a binary choice. Hamoudi (2006) reports "gamble averse" subjects, who prefer a sure amount of money over a gamble, where the lower of the two amounts that can be won in the gamble is equal to the sure amount.
} 
avoid it, thus the more often the subject will on average pay to avoid it.

Third, to measure a degree of rationality, we count the number of times subjects chose the dominated alternative in each of the five choice problems depicted in Figure 4. This measure takes on integer values from zero to five. The more subjects prefer dominated choices, the higher this measure.

\subsection{Experimental Procedures}

\subsubsection{Subject Pool}

In February of 2006, we held two sessions in the district of Cañete (in the Costa) and five sessions in the Mantaro river valley (in the Central Sierra). All seven communities are rural communities, where agriculture is the main livelihood. These communities do not specialize in a particular crop, yet maize and potato are the dominant ones. Forty two percent of our sampled farmers plant potato as their main crop, while $31 \%$ plant maize as their main crop. These crops are typical peruvian crops and are consumed locally and also sold in larger domestic markets.

In Cañete, we held one session with 19 subjects in Unanue, a community with just over 200 dwellings, and the other with 25 subjects in La Pampilla, a community with 60 dwellings. In the Mantaro river valley, we alternated sessions on either shore and each community was located in a different district. ${ }^{9}$ In the district of Paccha, we ran a session with 25 subjects from the community Buenos Aires (which has a population of 40 dwellings). In the district of Acolla, we ran another session with 25 subjects in Tambopaccha, a community with 80 dwellings. In the district of Matahuasi, we had 25 subjects from Yanamuclo (population: 300 dwellings). In the district of Orcotuna, we had 15 subjects from the community San

\footnotetext{
${ }^{9}$ We did this to minimize potential contamination from one session to the other in this densely populated region. Because kinship ties are strong in contiguous communities and weak across the river and noncontiguous communties, it is unlikely that word would travel quicker than the experimenters and surveyors from one field site to the other.
} 
Antonio (population: 35 dwellings). Finally, in the district of Sicaya, we had 25 subjects in Anexo La Libertad, a community with 95 dwellings. ${ }^{10}$

We visited each of the seven communities several days in advance to recruit subjects with the help of the community leaders, who also helped arrange the locales (schoolrooms or community halls) in which to run the session. Subjects were recruited based on the following criteria: they had to be of legal age (18 and above), be farmers, reside in the community where the session was to be held, and had to have basic literacy and numeracy skills.

Since the community leaders played an important role in recruiting subjects for the session, it is unlikely that we have a random sample. ${ }^{11}$ However, given the small sizes of the communities that we visited, our subjects are representative of their communities. For instance, since subjects did not come from the same households, a session with 25 subjects would represent 25 different households. Thus, in a community with 40 dwellings (such as Buenos Aires, Paccha), our session involved subjects from more than $50 \%$ of households. At the very least, in the case of Yanamuclo (Matahuasi), we sampled from just under $10 \%$ of households.

\subsubsection{Experimental Sessions}

We ran our sessions as laboratory experiments in the field. Subjects were given a show up fee of $10 \mathrm{~S} /$. upon arrival to cover their transportation and opportunity cost, which is roughly what an agricultural laborer earns in a day. Paying the show up fee immediately helps to build trust in the incentivized part of the experiment. Two of our surveyors, each native Spanish speakers, gave the instructions in all seven sessions reading from a script. ${ }^{12}$ The subjects were given a booklet containing the forty-four decisions. ${ }^{13}$ Each page of the booklet

\footnotetext{
10 The population data are from the 1999 Peruvian pre-census.

11 It was necessary to involve the community leaders so as to ensure the community's cooperation.

12 The English instructions are provided in Appendix 1. The instructions, given in Spanish in Peru, are a translation of the English instructions (available upon request).

13 These decisions consisted of the fourteen decisions in RM, AM, and DC plus the questions with additional alternatives in the choice set, which we do not analyze here.
} 
contained one decision. For each decision, subjects indicated their choice by pen. After subjects completed their booklets we verified that each page had exactly one choice marked on it. To control for the effects of order in presenting the choices, the order of the decisions as well as the left/right presentation of the gambles was randomly determined separately for each subject.

The gambles were implemented by drawing chips out of a bag. For this we used three separate bags, one for each type of randomization required by the experiment. The first bag contained forty-four numbered chips and determined which page of the booklet would be selected for payment. The second bag contained five blue and five yellow chips and determined the outcome of a 50/50 gamble with known probabilities. The third bag contained a number of blue and yellow chips which we determined randomly by drawing from a uniform distribution from all possible combinations of yellow and blue chips just before the session. When subjects played the gambles, they were first asked which color they chose, blue or yellow, to represent the higher of the two possible payoffs. ${ }^{14}$ They then pulled a chip from the appropriate bag to determine their earnings. Subjects were permitted to see the composition of the chips in the ambiguous bag if they desired after the draw. No subject ever asked to do so. Subjects also pulled the chip that determined the choice that was played for pay.

The experiments were held in either a schoolroom or a public meeting room. Only the subjects and experimenters were in the room at the time of the experiments, and outside distractions were carefully minimized. Subjects with relatively poor vision or hearing were seated at the front of the room to facilitate understanding of the instructions.

One-hundred and sixty subjects participated in the experiments, with session sizes of approximately twenty. ${ }^{15}$ Subjects earned an average of $25 \mathrm{~S} /$. in addition to the $10 \mathrm{~S} /$. show up fee. The experiments lasted approximately one hour, and the entire time spent

\footnotetext{
${ }^{14}$ Charness and Gneezy (2003) used this experimental procedure.

15 Sample sizes in lab experiments in the field studying risk preferences in developing countries tend to be quite small. Our study compares in sample size with Binswanger (1980) who had 240 farmers and Shahbuddin et al. (1986) who had 202 farmers.
} 
on the experiments and the survey was approximately 4 hours per session. Subjects first participated in the experiment, then individually completed the survey, and then were paid their earnings from one randomly chosen gamble choice in private.

\section{Survey \& Construction of Variables of Interest}

\subsection{Survey}

When the experiment ended, subjects were directed towards the surveyors where they orally completed a socio-economic survey which lasted on average 30 to 45 minutes per subject. The survey contained several modules designed to shed light on the determinants of technology choice, as well as relevant socio-economic controls. Namely, the survey contained modules on demographics and education, dwelling construction and materials, economic activity and access to markets, infrastructure and services, agricultural production, history of family and farm crises and so on. The survey also included questions pertaining to the experiment, questions about lottery and gambling experiences.

\subsection{Constructing the Dependent Variables}

The agricultural module asked respondents questions about their agricultural experiences over the last year. Specifically, subjects were asked questions pertaining the top three crops planted in the last 12 months such as the years of experience with each crop and whether they at any time received technical assistance. For the main crop, they were then asked questions about the top three varieties that they've planted in the last 12 months, such as the name of each variety, the years of experience with the particular variety and whether they've received any technical assistance for each variety. In the empirical analysis below, we will restrict our attention to the top three varieties of each farmer's main crop.

We had to depart from standard definitions of 'adoption' because of the types of farming 
in our study communities. ${ }^{16}$ Since our study communities do not tend to specialize in one crop, restricting our analysis to say potato or corn farmers would require that we lose a majority of our observations. Furthermore, because we could only visit each community for a half day, a more detailed survey of all seed choices was impractical.

The names of the crop varieties allow us to identify which variety is traditional and which is modern. Thus, we construct one of our dependent variables as a binary variable which takes the value ' 1 ' if the farmer has at least one modern variety in her top three varieties for her main crop, and ' 0 ' otherwise. If a farmer has at least one modern variety then she can be considered an 'adopter'. According to this definition of adoption, our samples suggest that $64 \%$ of our subjects from the two Costa communities are adopters. Meanwhile, only $20 \%$ of our subjects from the five Sierra communities are considered to be adopters according to this definition. These differences are driven by the markedly different economic and ecological environments in these two very different geographical regions.

It is possible that the labeling of seeds is prone to error. For instance "clover" could be correctly labeled as a traditional variety, but it could also be a coding or reporting error if the farmer meant "red clover", which instead would be a modern variety. This type of error could understate the true adoption rate. We thus propose to use a second dependent variable which would be less sensitive to such reporting errors: whether the farmer diversifies across varieties in the last 12 months. While this variable does not directly measure the adoption of new varieties, it does indicate the degree to which the farmer is (or has been) willing to try new or different things. This variable is constructed as a binary variable which takes the value of ' 1 ' if the farmer plants at least 2 or 3 varieties of the main crop, and ' 0 ' if the farmer only plants 1 variety.

The extent of variety diversification also varies across the two regions of our analysis:

\footnotetext{
${ }^{16}$ For instance, Conley and Udry (2006) focus on pineapple, while Duflo et al. (2006) focus on chemical fertilizers. In most other studies, the technology decision under analysis pertains to one particular new technology.
} 
only $11 \%$ of the Costa sample diversifies in this way, while $53 \%$ of the Sierra sample does. Diversification is typically thought of as a risk management strategy. This is certainly the case for crop diversification, as carefully chosen crops often face negatively co-variant risks. While variety diversification may share some element of risk management strategy (e.g. di Falco, Chavas and Smale (2006)), it also says something about the farmer's propensity to try something new or a different technology for a particular crop, and thus technology adoption by extension. In fact, our analysis allows us to evaluate whether variety diversification is driven by an adoption motive rather than a risk management motive. If it were purely risk management, we would not expect ambiguity aversion to be a significant predictor. However, if ambiguity aversion happens to predict variety diversification, then it is likely related to new technology adoption. Farmers typically have accurate beliefs about yield distributions of traditional varieties. If the portfolio of varieties includes only traditional varieties, then ambiguity aversion should not matter for diversification. However, since the farmer typically does not know the yield distribution of modern varieties, then ambiguity aversion would affect diversification of varieties if the portfolio includes modern varieties.

\subsection{Constructing the Main Explanatory Variables}

To determine which variables to include as explanatory variables in the technology choice regressions, we are driven by the hypotheses identified by the literature and laid out in section 2 above. We take each in turn and describe which variables we use to test each hypothesis.

Hypothesis 1 addresses the potentially important role that risk preferences might have in determining technology choice. Our risk preference measure, described in section 3.4., is decreasing in risk aversion. Thus, according to Hypothesis 1, one would expect a positive association between our risk preference measure and whether the farmer has planted a new or modern variety.

According to Hypothesis 2, ambiguity averse individuals are less likely to choose new or 
modern varieties. Thus, given our ambiguity measure described in section 3.4, this hypothesis would imply a negative association between ambiguity aversion and whether the farmer has planted a new or modern variety.

According to Hypothesis 3, technology adoption is decreasing in non-rational behavior. Our measure for non-rational behavior, described in section 3.4., is the number of times that subjects chose a payoff dominated option. According to Neoclassical theory of expected utility maximization, subjects should not choose such a dominated option. However, as shown in Table 1 , the average subject chose a dominated choice 1.756 times out of $5 .^{17}$ Subjects who make such decisions would be slower to adopt new varieties and so we would expect a negative effect of this measure on technology adoption.

Hypothesis 4 related to non-behavioral determinants of technology adoption. First, it suggests that technology adoption is inversely related to poverty. While our survey does not include information about income or consumption, we are able to construct an 'Unmet Basic Needs Index' (UBNI) to approximate a farmer's poverty status. ${ }^{18}$ We follow the Peruvian Statistical Agency's formula for the UBNI which takes into account the materials used in the construction of the dwelling walls, floors and roofs, and whether the dwelling has electricity, running water and sanitation. The higher the UBNI, the poorer the farmer. We would expect the UNBI to be negatively related to our dependent variables.

Second, Hypothesis 4 suggests that technology adoption is inversely related to borrowing constraints and the ability to save. While our survey did not collect information about savings or credit history, we do have information about how long it takes the farmer to

\footnotetext{
${ }^{17}$ See also Engle-Warnick, Escobal and Laszlo (2006) for a similar effect.

18 Many argue that an Unmet Basic Needs Index does more to identify a chronically poor individual than income or consumption because it is less sensitive to transitory income shocks. Furthermore, it is subject to significantly less measurement error because of the simplicity and verifiability of the questions that are asked in the survey. To adequately measure income or consumption in a survey would require a lengthy questionnaire which would involve a very large number of questions pertaining to income from various sources over a relatively long period of time (usually from a month to a year) or detailed consumption expenditures data. To construct an Unmet Basic Needs Index, a simple one page questionnaire typically suffices and is a snapshot of current living conditions.
} 
reach the nearest credit branch, which is what we use to proxy for access to credit and thus borrowing constraints. Thus, the further the farmer is from the branch, the more credit constrained she is and thus the less likely she is to adopt a new technology.

Third, Hypothesis 4 suggests that learning by doing is an important determinant of technology adoption. Years of experience proxies for learning by doing. Our data provides us with several measures of experience: years of experience with each of the top 3 crops and with each of the top three varieties of the main crop. We use two of these: years of experience with the main crop and years of experience with the main variety of the main crop. For learning by doing, the former measure should be the more appropriate one. If learning by doing matters, then we would expect that the longer a farmer has been growing a particular crop, the more likely she is to try a new variety. The years of experience with the main variety of the main crop, however, is likely to be negatively correlated with technology adoption, because adopters might have switched more frequently than non-adopters and so would de facto have less experience with a given variety.

Finally, Hypothesis 4 suggests that social learning (learning from others) is an important determinant of technology adoption. A farmer is more likely to adopt a new variety if others in the community have already done so, because she can learn from their experience. We construct a crude measure by taking the proportion of all other subjects who have also planted a modern variety, planted a new variety or diversified across varieties. ${ }^{19}$

The survey provides us with additional control variables, such as age, gender, and marital status. In addition, we utilize information about the farm (if it is owned by the respondent, the size of the land and if it is irrigated), how far the household resides from the closest agricultural extension office and how well respondents fared in a simple math test. ${ }^{20}$ From the

\footnotetext{
${ }^{19}$ This proxy for social learning suffers from the reflection problem, because a positive association between the social learning variable and the dependent variable might be explained by a third unobserved factor. Unfortunately, the survey does not include any other information that could be used to proxy for social learning.

${ }^{20}$ Subjects were asked simple algebra questions: $7 \times 3-4=$ ?; $12 \times 2-0.5=$ ?; and $31 \div 2=$ ?. The math index simply counts the number of correct answers.
} 
survey responses we are able to identify the farmer's educational attainment, and we include in our regression whether the farmer has completed primary school but has attained less than completed secondary school, whether she has completed secondary school, and whether she has completed any post-secondary school. The omitted category in the regressions is having attained less than completed primary school. Education would be positively related to adoption.

\subsection{Descriptive Statistics of the Explanatory Variables}

Figures 5, 6 and 7 present the distributions of each of our behavioral measures. We measure risk preferences by counting the number of times subjects chose the risky gamble. The histogram of this measure is presented in Figure 5. The distribution of responses is distributed around a mode of 2 . We measure ambiguity preferences by counting the number of times subjects chose to pay to avoid the ambiguous gamble (Figure 6). We measure 'irrationality' by counting the number of times (out of 5) subjects chose the dominated gamble. The distribution of responses, presented in Figure 7, is decreasing after 1. The degree of heterogeneity in responses for all three measures is striking.

Table 1 presents the descriptive statistics of all of the explanatory variables. The average participant in the experiment is survey is about 44 years old, most likely the head of the household and married and is almost equally likely to be male or female. However, we have a slightly higher proportion of women in the Costa sample than in the Sierra sample. Educational attainment is very heterogeneous with almost one third of the sample having attained less than completed primary school, almost one third having attained completed primary but less than completed secondary, and 14\% having some post-secondary schooling. Math skills, as measured by the math index, are weak, with the average subject giving less than one correct answer out of three. ${ }^{21}$ However, subjects fared somewhat better in the

\footnotetext{
21 The math index is nonetheless strongly correlated with educational attainment.
} 
math skills test in the Sierra sample than in the Costa sample.

On average, most participants own all or part of the land on which they work (except for the Costa where just under half own), and in most cases this land, which measures an average of 1.945 hectares, is irrigated. Average land size is greater in the Costa than in the Sierra, reflecting both the geographic and economic differences across the two regions. Subjects on average have 12 years of experience with the main crop. This is mostly driven by the Sierra sample where participants have about twice as much experience with the main crop than in the Costa. A similar trend is true also for the years of experience with the main variety of the main crop. Technical assistance is far more present among the Costa participants than the Sierra participants, reflecting again the economic differences between the regions. The Costa is generally more developed than the Sierra, and access to markets and infrastructure is generally better. This is also evident in the time it takes session participants to reach the closest agricultural extension office or credit office. Given the differences between the Costa and the Sierra, the regressions will include regional or session controls.

The behavioral parameters of interest have similar means across the two regional subsamples. However, it would appear that the Sierra participants are slightly more risk averse and less ambiguity averse than their Costa counterparts. They are also more likely to choose more dominated choices.

There is some evidence that the modern varieties of the major crops (e.g. potato and corn) tend to have higher yields than traditional ones. For instance, according to UNALM (2006), newly introduced potato varieties have a higher mean yield than older varieties, and their variability is larger. Our discussions with local non-profit organizations involved in agricultural extension corroborated this trend for potatoes. ${ }^{22}$ We have additional information about yield profitability of new varieties from our survey. We asked our subjects why they

\footnotetext{
${ }^{22}$ According to a representative of INIA (Instituto Nacional de Investigación y Extensión Agraria, an extension office of the Ministry of Agriculture in the Mantaro river valley) local potato yield grew from 8 tons per hectare in 1993 to 12.5 tons in 2005. The representative attributes this growth to the introduction of modern varieties.
} 
adopted or didn't adopt a new variety in the last 12 months. For those that adopted a new variety, $70 \%$ said they did so because they heard that the new variety has a higher yield. For those that did not adopt a new variety, only $17 \%$ suggested that it was because they believed new varieties have lower yield.

\section{Results}

\subsection{Risk Preference, Dominance, and Ambiguity Measures}

Before analyzing the effects of our behavioural measures on technology choice, we begin by discussing how they correlate with the observable socio-economic characteristics. Specifically, for each behavioral measure (RM, AM and DC), we estimate:

$$
Y_{i}=\mathbf{X}_{\mathbf{i}}^{\prime} \beta_{1}+\mathbf{Z}_{\mathbf{i}}^{\prime} \beta_{2}+\epsilon_{i}
$$

where $Y_{i}$ is the behavioral measure of interest (RM, AM or DC), $\mathbf{X}_{\mathbf{i}}$ is a vector of respondent characteristics (demographics, education and marital status), $\mathbf{Z}_{\mathbf{i}}$ is a vector of household, farm and regional controls, and $\epsilon_{i}$ is a stochastic disturbance term. All regressions were run using ordered probits. ${ }^{23}$

Table 2 presents the determinants of risk preference, ambiguity aversion and dominance. The first column presents the results for our measure of risk preference (recall the dependent variable is decreasing in risk aversion). We find that individuals from larger households tend to make riskier decisions, that poorer households are more risk averse and that farmers that own all or part of their land are also more risk averse than farmers who rent their land. That poverty is positively associated with risk aversion substantiates a claim made in Duflo (2004): poverty may have a direct effect on decision-making by affecting the decision-making process. That land-ownership is also positively associated with risk aversion could be reflecting the

\footnotetext{
23 The regressions were also run using tobits and poisson regressions (results not shown here), but the results are not qualitatively sensitive to the model used.
} 
notion that land owner-operators have an incentive to undertake safer decisions for fear of jeopardizing future profitability of the land. ${ }^{24}$

The measure of ambiguity aversion, that is the number of times that subjects paid to avoid the ambiguous gamble, seems to only be significantly affected by household size (negatively) and with residing in the Costa (positively) (see the second column of Table 2). The mildly positive effect of being in the Costa might simply be picking up cultural differences between the two sub-samples.

The determinants of the number of dominated choices are presented in the last column of Table 2. Age is positively associated with making dominated choices, while how well subjects performed in the math questions is inversely associated with making dominated choices. Older individuals are less educated and are likely making irrational decisions here. Restricting the sample to ages below 60 (results not shown here) eliminates the effect of age on dominated choices. However, the effect of the math index on dominated choice is robust to such a sample restriction. Clearly, numeracy (basic math skills) appears to matter in making what appear to be irrational choices.

\subsection{Regression Results}

To analyze the effect of our behaviorial measures (RM, AM and DC), we estimate the following regressions:

$$
D_{i}=\alpha_{1} R M_{i}+\alpha_{2} A M_{i}+\alpha_{3} D C_{i}+\mathbf{X}_{\mathbf{i}}^{\prime} \gamma_{1}+\mathbf{Z}_{\mathbf{i}}^{\prime} \gamma_{2}+\eta_{i}
$$

where $D_{i}$ is either whether one of the top three varieties of the farmer's main crop is a modern variety or whether the farmer diversifies across varieties for the main crop, $\mathbf{X}_{\mathbf{i}}^{\prime}$ is a vector of variables including respondent characteristics (demographics, education and marital status),

\footnotetext{
${ }^{24}$ One could argue that the effect is reflecting reverse causality: more risk averse individuals are less likely to hold land. However, land holdings in rural Peru are generally passed down from one generation to another following a substantial land reform in the 1980s.
} 
$\mathbf{Z}_{\mathbf{i}}^{\prime}$ includes household, farm and regional controls and $\eta_{i}$ is a stochastic disturbance term. The variables in $\mathbf{Z}$ allow us to test Hypothesis 4 described above. ${ }^{25}$

Tables 3 and 4 analyze the study farmers' technology choice decisions. The dependent variables, described above, are first whether one of the top three varieties of the farmer's main crop is a modern variety (Table 3) and whether the farmer diversifies across varieties for the main crop (Table 4). Both tables include two specifications. The difference between the two is which behavioral measures are included. In the first specification, only the risk and ambiguity preference measures are included, while in the second specification, we also add the preference for dominated alternatives.

We first discuss the effects of our behavioral parameters, which help us address Hypothesis 1 (risk preferences), Hypothesis 2 (ambiguity preferences), and Hypothesis 3 (irrationality). Table 3 suggests that these parameters are not that important in whether one of the top three varieties of the main crop is a modern variety. Even the preference for dominated choices does not have any predictive power in this regression. As discussed above, this variable is prone to measurement error: a variety might be incorrectly labeled traditional when it is modern, or incorrectly labeled modern when it is traditional. So we turn our attention to our alternate dependent variable, whether the farmer diversifies across varieties, for further evidence of the effect of risk and ambiguity preferences, as well as irrationality, on technology choice.

The effect of these behavioral parameters in the decision to diversify across varieties is presented in Table 4. As discussed above, diversifying across varieties may reflect two decision processes: it may pick up a farmer's risk management strategy or also the farmer's propensity to try new things and thus her propensity to adopt a modern variety. Our behavioral

\footnotetext{
25 The specifications are slightly different for the two different dependent variables. Specifically, in the case of the first dependent variable, we include the proportion of subjects in the session who also have a modern variety as one of their top three varieties of the main crop to account for learning from others. However, a similar variable is not included for the second dependent variable because of insufficient variability the data. Nonetheless, we include session controls in this case, which would control for session-level effects.
} 
measures can help distinguish between these two decision processes - if diversifying across varieties simply reflects a risk management strategy, then we would expect risk preferences to matter, and not ambiguity aversion. On the other hand, if diversifying across varieties were reflecting the propensity to try new things and thus modern varieties, then we would expect ambiguity aversion to matter. In other words, suppose that diversifying across varieties meant that the farmer held a portfolio of traditional varieties. Then, since farmers tend to know the yield distribution of traditional varieties, their aversion to ambiguity should be irrelevant. Conversely, suppose that diversifying across varieties includes at least one modern variety. In this case, since modern varieties tend to have an unknown yield distribution, farmers who are ambiguity averse will be less likely to adopt a modern variety and thus less likely to diversify across varieties.

This is exactly what we find in Table 4. The more ambiguity averse farmers are, the less likely they are to diversify across varieties. Surprisingly, risk aversion does not influence this decision, which we would have expected if diversification were more a risk management strategy. ${ }^{26}$ This result is robust to the inclusion of the dominance preference measure, which is in itself insignificant. The result that risk aversion does not affect technology choice does not necessarily invalidate the importance of this behavioral parameter in technology adoption - recall that our dependent variable, especially the one used in Table 4, is different than those used by the studies surveyed by Feder et al. (1985): it arrives at technology adoption indirectly. However, the importance of the ambiguity aversion measure lends strong evidence in favor of variety diversification as adoption-like behavior for this sample of farmers.

Hypothesis 4 suggested that our unmet basic needs index would be negatively correlated with the having planted a modern variety. However, results in Table 3 suggest this is not the case - the coefficient on the UBNI is statistically insignificant. Hypothesis 4 also suggested that the time to reach the closest credit office, to proxy for the ability to save or borrow,

\footnotetext{
${ }^{26}$ The insignificance of the risk preference coefficient is robust to the exclusion of the ambiguity aversion coefficient.
} 
would be negatively related to the dependent variable. Again, as can be seen in Table 3, this hypothesis is rejected on the basis of the insignificance of the coefficient on the time to reach the closest credit office. The learning by doing hypothesis would suggest that age and experience with the main crop would positively predict the planting of a modern variety. Age is strongly positively related to planting a modern variety - learning by doing seems to be a determining factor in modern technology adoption in our sample. Years of experience with the main crop is, however, statistically insignificant. It is interesting to note that the years of experience with the main variety of the main crop is negatively related to planting a modern variety. Though this might seem counter intuitive at first, it is actually entirely consistent with technology adoption: adopters are more likely to switch from one variety to another (consistent with the target learning by doing model of Jovanovic and Nyarko (1996), see also Engle-Warnick and Laszlo (2006)), thus generating a negative association between years of experience with a given variety and adoption. ${ }^{27}$ Learning from others would suggest that farmers are more likely to adopt modern varieties if their neighbors have already done so. We find, however, that the proportion of other subjects in the session who plant at least one modern variety does not have an effect on the farmer's decision. ${ }^{28}$

Finally, the regressions in Table 4 present interesting results pertaining to the remaining co-variates. In the case of diversification, poverty is positively related to diversification, rejecting Hypothesis 4. Learning by doing also seems to be working in this case, as the years of experience with the main crop is strongly positively and significantly related to diversification. Also, the educational attainment of the farmer is statistically significantly positively related to diversification, having completed primary or secondary causes the farmer to diversify more than if she had attained less than primary schooling.

\footnotetext{
27 The argument can be seen also from its reciprocal, illustrated by the following idiom: "You can't teach an dog new tricks".

28 Identifying the causal effect here is difficult because of the reflection problem. We reran our model without this proxy for social learning in case the reflection problem contaminated our other coefficients. The results, specifically pertaining to our variables of interest (RM, AM, and DC), are robust to this restriction.
} 


\section{Discussion}

This study is the first to attempt to distinguish empirically between risk aversion and ambiguity aversion in farmers' technology choices in developing countries. Although much of the literature focuses on the role of risk aversion as a possible behavioral explanation for the lack of technology adoption among the rural poor, we find evidence that ambiguity matters more in our sample of Peruvian farmers.

New or modern technologies are characterized by unknown yield distributions, while traditional technologies are characterized by yield distributions over which the farmer has relatively accurate beliefs. Thus, it seems reasonable that the adoption of modern technologies would depend more on farmers' aversion to ambiguity than their aversion to risk.

Our methodological contribution is to combine unique data from a lab experiment in the field to measure behavioral parameters such as risk and ambiguity preferences, and survey data on actual farm technology choices and socio-economic characteristics of the farmer, all collected in the same experimental session. By doing so, we advance our understanding of the experimental measures we use to explain the technology choices. 


\section{References}

Antle, J.M. and Crissman, C.C. (1990). "Risk, Efficiency, and the Adoption of Modern Crop Varieties" Evidence from the Philippines," Economic Development and Cultural Change, 38:3:517-537.

Becker, G., M. DeGroot, and J. Marschak (1964). "Measuring Utility by a Single-Response Sequential Method," Behavioral Science, 8:4:293-315.

Besley, T. and A. Case (1993). "Modeling Technology Adoption in Developing Countries," American Economic Review Vol. 83:2:396-402.

Binswanger, H. (1980). "Attitudes toward Risk: Experimental Measurement in Rural India", American Journal of Agricultural Economics, 62:3:395-407.

Charness, G. and U. Gneezy (2003). "Portfolio Choice and Risk Attitudes," SSRN working paper.

Conley, T. and C. Udry (2006). "Learning about a New Technology: Pineapple in Ghana," Yale Working Paper.

di Falco, S., J.-P. Chavas and M. Smale (2006). "Farmer Management of Production Risk on Degraded Lands: The Role of Wheat Genetic Diversity in Tigray Region, Ethiopia," Working Paper, CSERGE School of Environmental Sciences.

Duflo, E. (2004). "Are the Poor Rational?" in What Have We Learnt About Poverty? (A. Banerjee, R. Benabou, D. Mookherjee, eds.), Oxford University Press.

Duflo, E., M. Kremer and J. Robinson (2006). "Why Don’t Farmers Use Fertilizer? Evidence from Field Experiments in Eastern Kenya," MIT Working Paper.

Eckel, C. and P. J. Grossman (2003). "Forecasting Risk Attitudes: An Experimental Study of Actual and Forecast Risk Attitudes of Women and Men," Virginia Tech Department of Economics Working Paper.

Eckel, C., J. Engle-Warnick, and K. Johnson (2005). "Adaptive elicitation of risk preferences," Working paper, McGill University.

Eckel, C., V. Hotz, C. Johnson, L. Rubalcava, G. Teruel, D. Thomas, H. Conroy, and A. Hamoudi (2006). "Measures of risk, time preferences and socio-economic status," 2006 Regional Meeting Economics Science Association.

Ellsberg, D. (1961). "Risk, Ambiguity, and the Savage Axioms," Quarterly Journal of Economics, 75:4:643-669.

Engle-Warnick, J. and S. Laszlo (2006). "Learning by doing in an ambiguous environment," Working paper, McGill University. 
Engle-Warnick, J., J. Escobal and S. Laszlo (2006). "The Effect of an Additional Choice on Measured Risk Preferences in a Field Experiment," Working paper, McGill University.

Feder, G. (1980). "Farm Size, Risk Aversion and the Adoption of New Technologies under Uncertainty," Oxford Economic Papers, 32:2:263-283.

Feder, G. R. Just and D. Zilberman (1985). "Adoption of Agricultural Innovations in Developing Countries: A Survey," Economic Development and Cultural Change, January.

Foster, A. and M. Rosenzweig (1995). "Learning by Doing and Learning from Others: Human Capital and Technical Change in Agriculture," Journal of Political Economy 103:6:1176-1209.

Hamoudi, A. (2006). "Risk Preferences in Households and Families", UCLA working paper.

Holt, C. and S. Laury (2002). "Risk Aversion and Incentive Effects in Lottery Choices," American Economic Review, 96:1644-1655.

Jovanovic, B, and Y. Nyarko (1996). "Learning by Doing and the Choice of Technology," Econometrica 64:6:1299-1310.

Knight, F. (1921). Risk, Uncertainty and Profit Boston: Houghton Mifflin.

Knight, J., W. Sharada and T. Woldehanna (2003). "The Role of Education in Facilitating Risk-Taking and Innovation in Agriculture," Journal of Development Studies, 39:6:122.

Manski, C.F. (1993). "Identification of Endogenous Social Effects: the Reflection Problem," Review of Economic Studies 60:3:531-542.

Munshi, K. (2004). "Social Learning in a Heterogeneous Population: Technology Diffusion in the Indian Green Revolution," Journal of Development Economics 73:1:185-215.

Rigotti, L., M. Ryan and R. Vaithianathan (2003). "Tolerance of Ambiguity and Entrepreneurial Innovation," Duke University Manuscript.

Shahabuddin, Q., S. Mestleman and D. Feeny (1986). "Peasant Behavior Toward Risk and Socio-Economic And Structural Characteristics of Farm Households in Bangladesh," Oxford Economic Papers 38:122-130.

Universidad Nacional Agraria La Molina (UNALM) (2006). "Papa UNALM Guisi" Website: http://www.lamolina.edu.pe/Investigacion/programa/papa/guisi.htm (Accessed October 13th, 2006). 
Table 1 - Descriptive Statistics

\begin{tabular}{lccc}
\hline \hline Variable & Total & Costa & Sierra \\
\hline Age & 43.870 & 43.205 & 44.130 \\
& $(14.655)$ & $(12.791)$ & $(15.353)$ \\
Household Head & 0.755 & 0.704 & 0.774 \\
Male & 0.553 & 0.409 & 0.609 \\
Married & 0.719 & 0.578 & 0.774 \\
Separated & 0.156 & 0.222 & 0.130 \\
Single & 0.119 & 0.178 & 0.096 \\
Less than Primary & 0.300 & 0.356 & 0.278 \\
Primary, Less than secondary & 0.350 & 0.333 & 0.357 \\
Secondary Completed & 0.206 & 0.200 & 0.209 \\
Post- Secondary & 0.144 & 0.111 & 0.157 \\
Math Index & 0.931 & 0.711 & 1.017 \\
& $(1.023)$ & $(0.944)$ & $(1.043)$ \\
Household Size & 5.377 & 6.023 & 5.130 \\
& $(2.283)$ & $(2.698)$ & $(2.063)$ \\
Unmet Basic Needs Index & 0.419 & 0.467 & 0.401 \\
& $(0.213)$ & $(0.221)$ & $(0.207)$ \\
Landsize (Hectares) & 1.945 & 2.590 & 1.731 \\
& $(1.931)$ & $(1.699)$ & $(1.963)$ \\
Owns all or part of land & 0.747 & 0.432 & 0.853 \\
Land is irrigated & 0.713 & 0.892 & 0.651 \\
Years experience with main crop & 12.127 & 6.597 & 13.936 \\
& $(11.498)$ & $(6.373)$ & $(12.224)$ \\
Years experience with main variety & 9.219 & 4.861 & 10.645 \\
& $(9.330)$ & $(6.197)$ & $(9.753)$ \\
Received technical assistance for main variety & 0.303 & 0.833 & 0.128 \\
Time to reach closest agricultural extension office & 43.150 & 20.209 & 52.118 \\
Time to reach nearest credit office & $(30.665)$ & $(15.064)$ & $(30.579)$ \\
& 46.647 & 19.698 & 57.182 \\
Number of risky choices in binary gamble & $(30.418)$ & $(9.412)$ & $(29.284)$ \\
Number of times paid to avoid ambiguity & 1.925 & 2.222 & 1.809 \\
& $(1.163)$ & $(1.166)$ & $(1.146)$ \\
Number of dominated choices & 2.350 & 2.756 & 2.191 \\
& $(1.578)$ & $(1.653)$ & $(1.527)$ \\
N(Max) & 1.756 & 1.578 & 1.826 \\
\hline \hline Standard deviation in brackets. & $(1.418)$ & $(1.390)$ & $(1.428)$ \\
\hline
\end{tabular}


Table 2 - Ordered Probit Results

\begin{tabular}{|c|c|c|c|}
\hline & \# of Risky Choices & $\begin{array}{l}\text { \# of Times Paid to } \\
\text { Avoid Ambiguity }\end{array}$ & $\begin{array}{c}\text { \# Dominated } \\
\text { Choices }\end{array}$ \\
\hline \multirow[t]{2}{*}{ Age } & 0.012 & 0.013 & 0.026 \\
\hline & $(0.009)$ & $(0.008)$ & $(0.009)^{\star \star \star}$ \\
\hline \multirow[t]{2}{*}{ Respondent is household head } & 0.287 & -0.008 & 0.092 \\
\hline & $(0.317)$ & $(0.266)$ & $(0.287)$ \\
\hline \multirow[t]{2}{*}{ Male $=1$} & -0.414 & 0.254 & 0.004 \\
\hline & $(0.282)$ & $(0.233)$ & $(0.233)$ \\
\hline \multirow[t]{2}{*}{ Married or living with partner } & 0.341 & 0.102 & -0.456 \\
\hline & $(0.352)$ & $(0.292)$ & $(0.368)$ \\
\hline \multirow[t]{2}{*}{ Separated, Widowed, divorced } & 0.066 & 0.270 & -0.064 \\
\hline & $(0.477)$ & $(0.399)$ & $(0.484)$ \\
\hline \multirow[t]{2}{*}{ Primary completed and less than Secondary completed } & -0.351 & 0.349 & -0.523 \\
\hline & $(0.429)$ & $(0.410)$ & $(0.449)$ \\
\hline \multirow{2}{*}{ Secondary completed } & -0.289 & -0.030 & -0.522 \\
\hline & $(0.472)$ & $(0.478)$ & $(0.497)$ \\
\hline \multirow[t]{2}{*}{ Post secondary } & -0.642 & 0.251 & -0.329 \\
\hline & $(0.563)$ & $(0.605)$ & $(0.646)$ \\
\hline \multirow[t]{2}{*}{ Math Index (0 --> 3) } & -0.114 & -0.195 & -0.282 \\
\hline & $(0.118)$ & $(0.119)$ & $(0.114)^{\star \star}$ \\
\hline \multirow[t]{2}{*}{ hhsize } & 0.094 & -0.140 & 0.108 \\
\hline & $(0.047)^{\star \star}$ & $(0.038)^{\star \star \star}$ & $(0.050)^{\star \star}$ \\
\hline \multirow[t]{2}{*}{ Unmet Basic Needs Index - Aggregate } & -1.494 & -0.310 & 0.126 \\
\hline & $(0.893)^{\star}$ & $(0.970)$ & $(0.935)$ \\
\hline \multirow[t]{2}{*}{ Landsize in hectares } & -0.025 & -0.026 & -0.058 \\
\hline & $(0.043)$ & $(0.062)$ & $(0.055)$ \\
\hline \multirow[t]{2}{*}{ Owns all or part of agricultural land } & -0.624 & -0.409 & -0.154 \\
\hline & $(0.306)^{\star \star}$ & $(0.285)$ & $(0.235)$ \\
\hline \multirow[t]{2}{*}{ Land is irrigated } & 0.165 & -0.057 & -0.017 \\
\hline & $(0.280)$ & $(0.275)$ & $(0.274)$ \\
\hline \multirow[t]{2}{*}{ Costa dummy } & 0.089 & 0.932 & $(0.351)$ \\
\hline & $(0.499)$ & $(0.502)^{\star}$ & $(0.482)$ \\
\hline Wald Chi-Squared & $47.89 * \star \star$ & $43.99 * \star \star$ & $80.20 * \star \star$ \\
\hline Pseudo R-Squared & 0.0875 & 0.0714 & 0.1123 \\
\hline Observations & 141 & 141 & 141 \\
\hline
\end{tabular}

Standard errors in parentheses. * significant at 10\%; ** significant at 5\%; ${ }^{\star \star \star}$ significant at 1\%. All regressions include session controls 
Table 3 - Probit Marginal Effects

\begin{tabular}{|c|c|c|}
\hline \multirow[b]{2}{*}{ Number of risky choices in binary gamble } & \multicolumn{2}{|c|}{$\begin{array}{c}\text { At Least One of the Top Three } \\
\text { Varieties of Main crop is A } \\
\text { Modern Variety }\end{array}$} \\
\hline & $\begin{array}{l}0.013 \\
(0.035)\end{array}$ & $\begin{array}{l}0.014 \\
(0.034)\end{array}$ \\
\hline Number of times chose to pay to avoid ambiguity in binary with ambiguous & $\begin{array}{l}-0.023 \\
(0.026)\end{array}$ & $\begin{array}{l}-0.021 \\
(0.025)\end{array}$ \\
\hline Number of dominated choices in Binary Dominated gamble & & $\begin{array}{l}-0.016 \\
(0.030)\end{array}$ \\
\hline Age & $\begin{array}{c}0.012 \\
(0.003)^{\star \star \star}\end{array}$ & $\begin{array}{c}0.012 \\
(0.003)^{\star \star \star}\end{array}$ \\
\hline Respondent is household head & $\begin{array}{l}-0.220 \\
(0.151)\end{array}$ & $\begin{array}{l}-0.213 \\
(0.150)\end{array}$ \\
\hline Male $=1$ & $\begin{array}{l}0.082 \\
(0.102)\end{array}$ & $\begin{array}{l}0.078 \\
(0.101)\end{array}$ \\
\hline Married or living with partner & $\begin{array}{l}-0.110 \\
(0.149)\end{array}$ & $\begin{array}{l}-0.125 \\
(0.147)\end{array}$ \\
\hline Separated, Widowed, divorced & $\begin{array}{c}-0.229 \\
(0.061)^{\star}\end{array}$ & $\begin{array}{c}-0.230 \\
(0.060)^{\star \star}\end{array}$ \\
\hline Primary completed and less than Secondary completed & $\begin{array}{c}-0.062 \\
(0.170)\end{array}$ & $\begin{array}{l}-0.062 \\
(0.169)\end{array}$ \\
\hline Secondary completed & $\begin{array}{l}0.179 \\
(0.266)\end{array}$ & $\begin{array}{l}0.185 \\
(0.265)\end{array}$ \\
\hline Post secondary & $\begin{array}{l}0.058 \\
(0.276)\end{array}$ & $\begin{array}{l}0.065 \\
(0.278)\end{array}$ \\
\hline Math Index $(0-->3)$ & $\begin{array}{l}0.018 \\
0.044\end{array}$ & $\begin{array}{l}0.013 \\
(0.045)\end{array}$ \\
\hline hhsize & $\begin{array}{l}-0.019 \\
(0.020)\end{array}$ & $\begin{array}{l}-0.017 \\
(0.020)\end{array}$ \\
\hline Unmet Basic Needs Index - Aggregate & $\begin{array}{l}-0.224 \\
(0.408)\end{array}$ & $\begin{array}{l}-0.203 \\
(0.405)\end{array}$ \\
\hline Landsize in hectares & $\begin{array}{c}-0.060 \\
(0.029)^{\star \star}\end{array}$ & $\begin{array}{c}-0.062 \\
(0.029)^{\star \star}\end{array}$ \\
\hline Owns all or part of agricultural land & $\begin{array}{l}-0.045 \\
(0.122)\end{array}$ & $\begin{array}{l}-0.043 \\
(0.121)\end{array}$ \\
\hline Land is irrigated & $\begin{array}{l}0.060 \\
(0.087)\end{array}$ & $\begin{array}{c}0.0633 \\
(0.088)\end{array}$ \\
\hline Proportion of other subjects in session who plant at least one modern variety & $\begin{array}{c}0.334 \\
(0.359)\end{array}$ & $\begin{array}{r}0.336 \\
(0.358)\end{array}$ \\
\hline Years experience with main crop & $\begin{array}{l}-0.005 \\
(0.006)\end{array}$ & $\begin{array}{l}-0.005 \\
(0.006)\end{array}$ \\
\hline Years experience with main variety of main crop & $\begin{array}{c}-0.012 \\
(0.007)^{\star}\end{array}$ & $\begin{array}{c}-0.012 \\
(0.007)^{\star}\end{array}$ \\
\hline Received technical assistance for main variety of main crop & $\begin{array}{l}0.080 \\
(0.138)\end{array}$ & $\begin{array}{l}0.079 \\
(0.137)\end{array}$ \\
\hline Time to reach closest agricultural extension office & $\begin{array}{l}0.000 \\
(0.002)\end{array}$ & $\begin{array}{l}0.000 \\
(0.002)\end{array}$ \\
\hline Time to reach closest credit office & $\begin{array}{l}0.000 \\
(0.002)\end{array}$ & $\begin{array}{l}-0.000 \\
(0.002)\end{array}$ \\
\hline Coast & $\begin{array}{c}0.412 \\
(0.266)^{*}\end{array}$ & $\begin{array}{c}0.407 \\
(0.268)\end{array}$ \\
\hline Wald Chi-Squared & $81.73^{\star \star *}$ & $81.39 * * *$ \\
\hline Pseudo R-Squared & 0.3849 & 0.3861 \\
\hline Observations & 133 & 133 \\
\hline
\end{tabular}

Robust standard errors in parentheses. ${ }^{*}$ significant at $10 \% ;{ }^{* \star}$ significant at $5 \%$; ${ }^{\star \star \star}$ significant at $1 \%$ 
Table 4 - Probit Marginal Effects

\begin{tabular}{|c|c|c|}
\hline \multirow[b]{2}{*}{ Number of risky choices in binary gamble } & \multicolumn{2}{|c|}{$\begin{array}{c}\text { Diversifies across Varieties (Two } \\
\text { or Three More Varieties of Main } \\
\text { Crop) }\end{array}$} \\
\hline & $\begin{array}{l}0.047 \\
(0.052)\end{array}$ & $\begin{array}{l}0.049 \\
(0.052)\end{array}$ \\
\hline Number of times chose to pay to avoid ambiguity in binary with ambiguous & $\begin{array}{c}-0.105 \\
(0.040)^{\star \star \star}\end{array}$ & $\begin{array}{c}-0.092 \\
(0.040)^{\star \star \star}\end{array}$ \\
\hline Number of dominated choices in Binary Dominated gamble & & $\begin{array}{l}-0.065 \\
(0.045)\end{array}$ \\
\hline Age & $\begin{array}{c}-0.012 \\
(0.006)^{\star}\end{array}$ & $\begin{array}{l}-0.010 \\
(0.006)\end{array}$ \\
\hline Respondent is household head & $\begin{array}{l}0.171 \\
(0.138)\end{array}$ & $\begin{array}{l}0.199 \\
(0.135)\end{array}$ \\
\hline Male $=1$ & $\begin{array}{l}0.006 \\
(0.138)\end{array}$ & $\begin{array}{l}-0.002 \\
(0.139)\end{array}$ \\
\hline Married or living with partner & $\begin{array}{l}0.198 \\
(0.140)\end{array}$ & $\begin{array}{l}0.139 \\
(0.149)\end{array}$ \\
\hline Separated, Widowed, divorced & $\begin{array}{l}-0.275 \\
(0.176)\end{array}$ & $\begin{array}{l}-0.273 \\
(0.180)\end{array}$ \\
\hline Primary completed and less than Secondary completed & $\begin{array}{c}0.528 \\
(0.244)^{\star}\end{array}$ & $\begin{array}{c}0.468 \\
(0.253)^{\star}\end{array}$ \\
\hline Secondary completed & $\begin{array}{c}0.640 \\
(0.184)^{\star \star}\end{array}$ & $\begin{array}{c}0.614 \\
(0.195)^{\star \star}\end{array}$ \\
\hline Post secondary & $\begin{array}{l}0.584 \\
(0.256)\end{array}$ & $\begin{array}{l}0.543 \\
(0.278)\end{array}$ \\
\hline Math Index (0 --> 3) & $\begin{array}{l}0.093 \\
(0.068)\end{array}$ & $\begin{array}{l}0.066 \\
(0.070)\end{array}$ \\
\hline hhsize & $\begin{array}{l}-0.010 \\
(0.026)\end{array}$ & $\begin{array}{l}0.003 \\
(0.027)\end{array}$ \\
\hline Unmet Basic Needs Index - Aggregate & $\begin{array}{c}1.747 \\
(0.735)^{\star \star}\end{array}$ & $\begin{array}{c}1.670 \\
(0.733)^{\star \star}\end{array}$ \\
\hline Landsize in hectares & $\begin{array}{c}0.189 \\
(0.059)^{\star \star \star}\end{array}$ & $\begin{array}{c}0.181 \\
(0.058)^{\star \star \star}\end{array}$ \\
\hline Owns all or part of agricultural land & $\begin{array}{l}-0.105 \\
(0.171)\end{array}$ & $\begin{array}{l}-0.077 \\
(0.170)\end{array}$ \\
\hline Land is irrigated & $\begin{array}{l}-0.032 \\
(0.205)\end{array}$ & $\begin{array}{l}0.018 \\
(0.200)\end{array}$ \\
\hline Years experience with main crop & $\begin{array}{c}0.022 \\
(0.008)^{\star \star \star}\end{array}$ & $\begin{array}{c}0.022 \\
(0.008)^{\star \star}\end{array}$ \\
\hline Years experience with main variety of main crop & $\begin{array}{c}0.002 \\
(0.009)\end{array}$ & $\begin{array}{l}0.002 \\
(0.009)\end{array}$ \\
\hline Received technical assistance for main variety of main crop & $\begin{array}{l}0.146 \\
(0.190)\end{array}$ & $\begin{array}{l}0.104 \\
(0.185)\end{array}$ \\
\hline Time to reach closest agricultural extension office & $\begin{array}{l}0.001 \\
(0.003)\end{array}$ & $\begin{array}{l}0.000 \\
(0.003)\end{array}$ \\
\hline Time to reach closest credit office & $\begin{array}{l}-0.003 \\
(0.003)\end{array}$ & $\begin{array}{l}-0.002 \\
(0.003)\end{array}$ \\
\hline Costa & $\begin{array}{c}-0.587 \\
(0.134)^{\star \star}\end{array}$ & $\begin{array}{c}-0.609 \\
(0.127)^{\star \star}\end{array}$ \\
\hline Wald Chi-Squared & $94.60 * \star \star$ & $100.87^{\star \star \star}$ \\
\hline Pseudo R-Squared & 0.5226 & 0.5301 \\
\hline Observations & 133 & 133 \\
\hline
\end{tabular}

Robust standard errors in parentheses. * significant at 10\%; ** significant at 5\%; ${ }^{\star \star \star}$ significant at 1\%. All regressions include session controls. 
Figure 1: 'Five Options’ Risk Preference Measurement Instrument
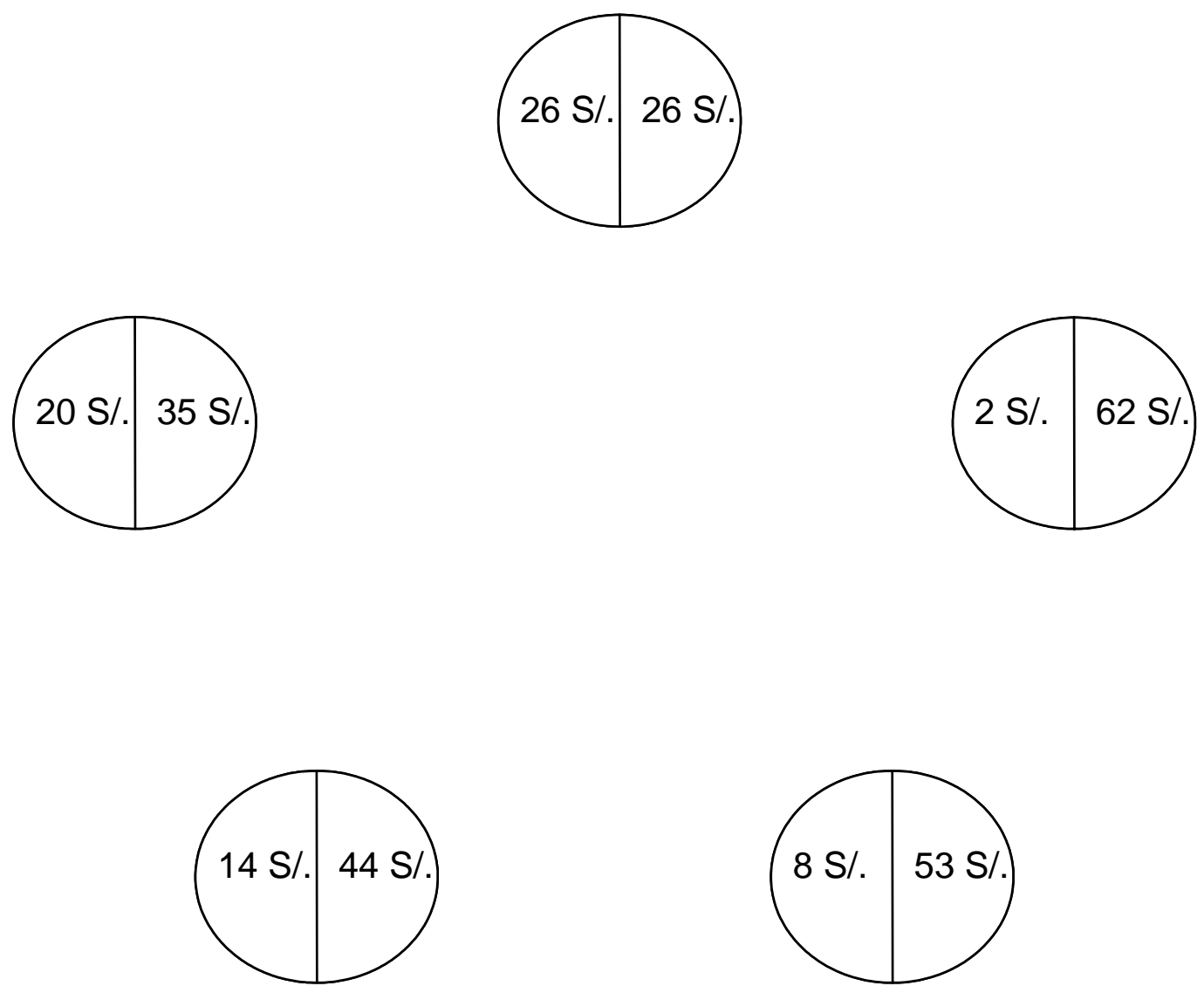
Figure 2: Decomposing the 'Five Options' Instrument into a Series of 'Binary Options' Instruments
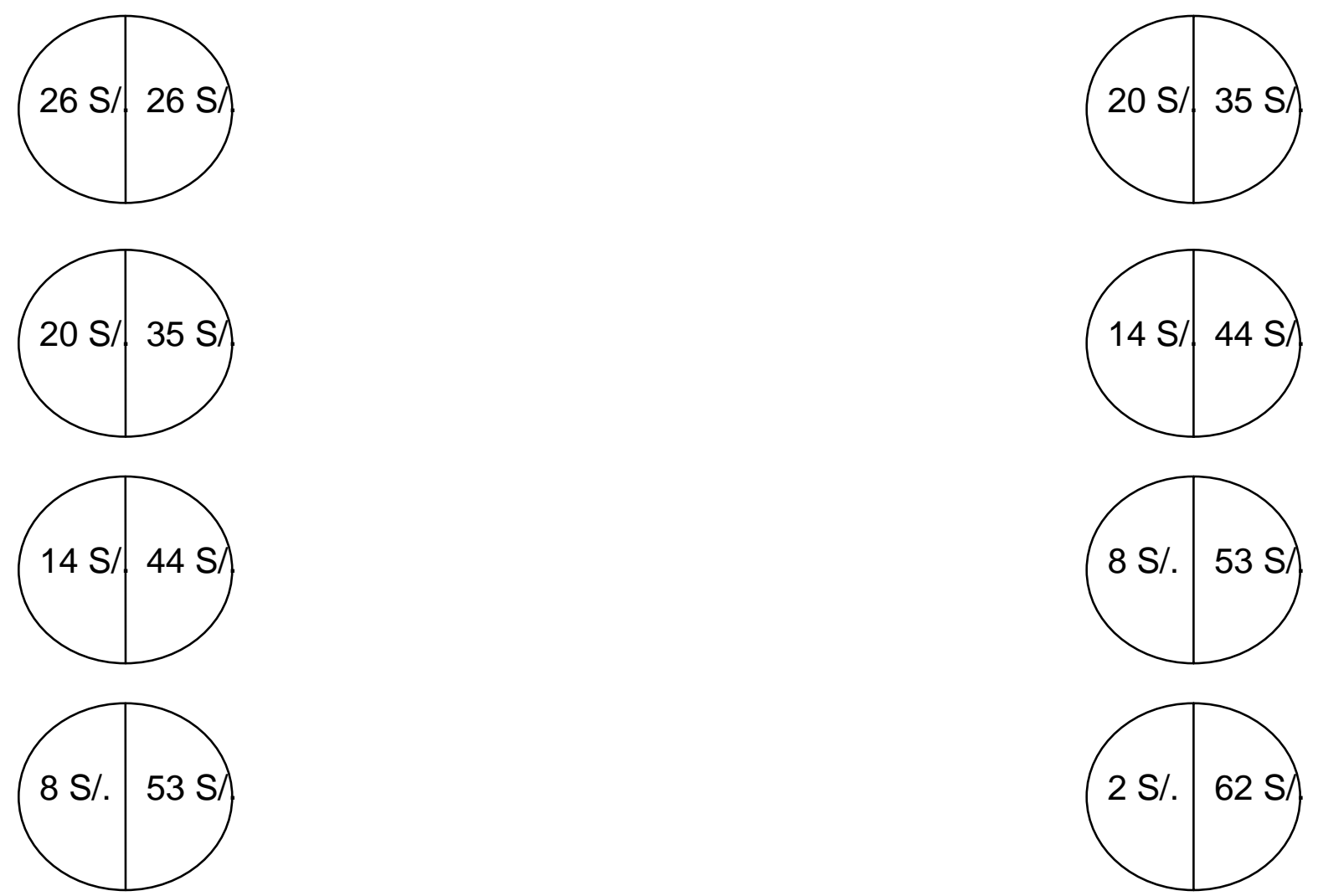
Figure 3: Binary Choices to Reveal Preferences for Ambiguity
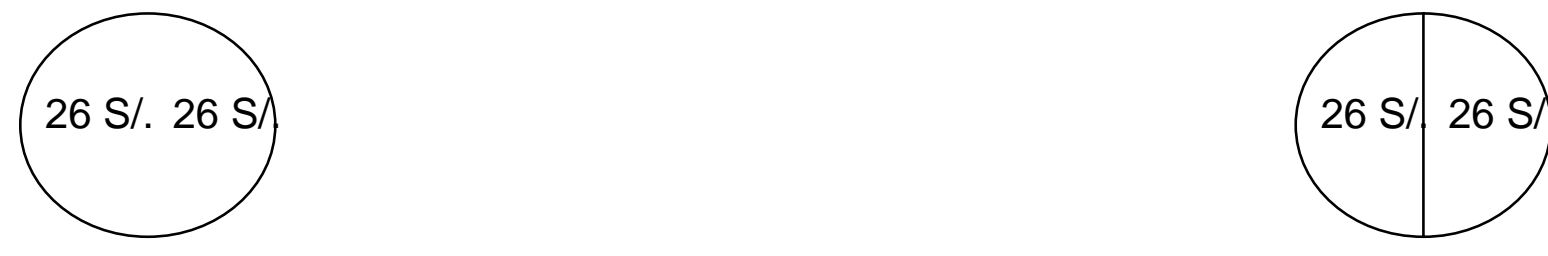

Precio S/0.50
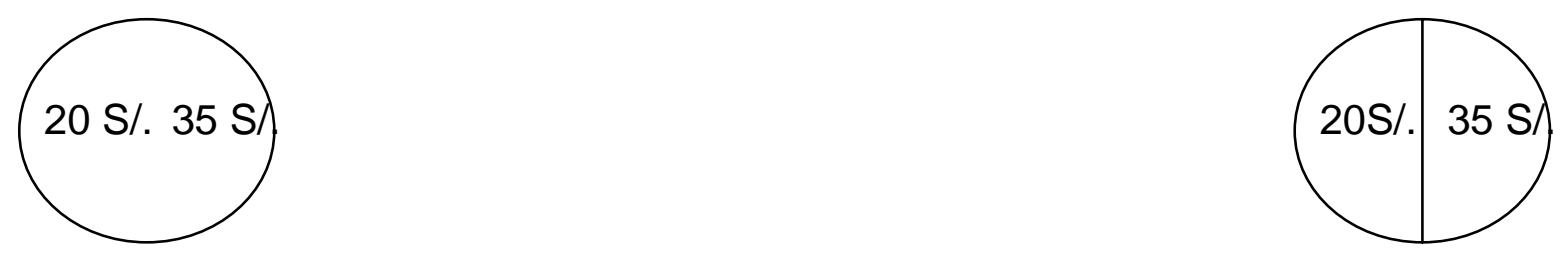

Precio S/0.50
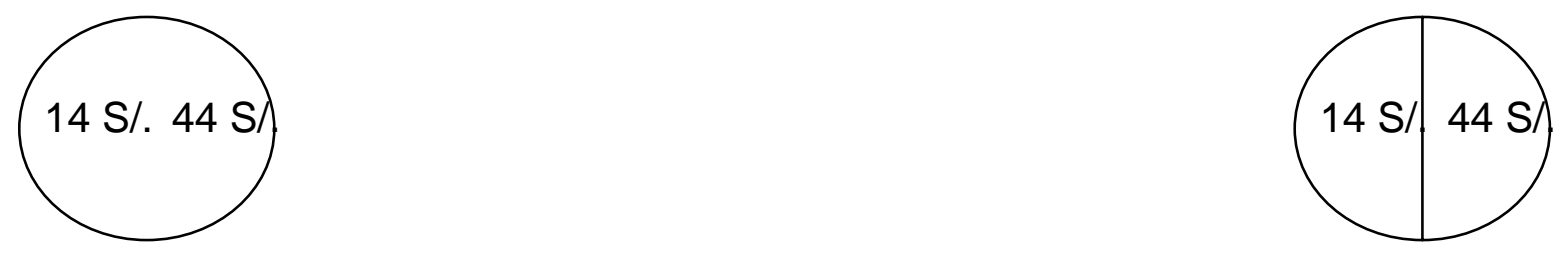

Precio S/0.50
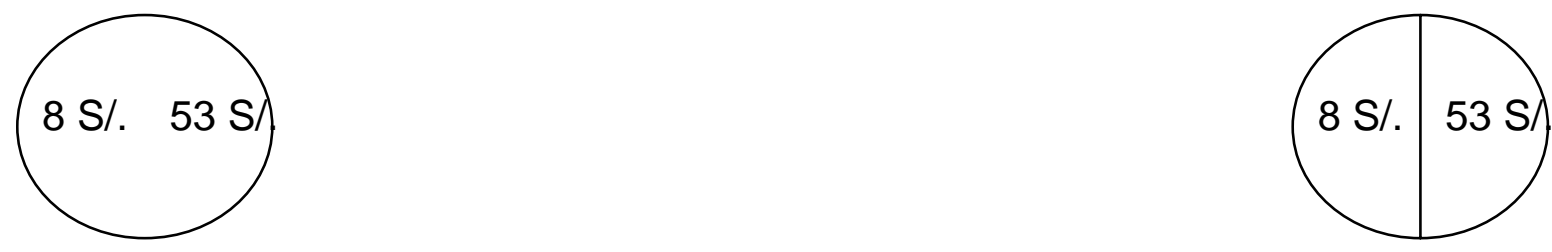

Precio S/0.50
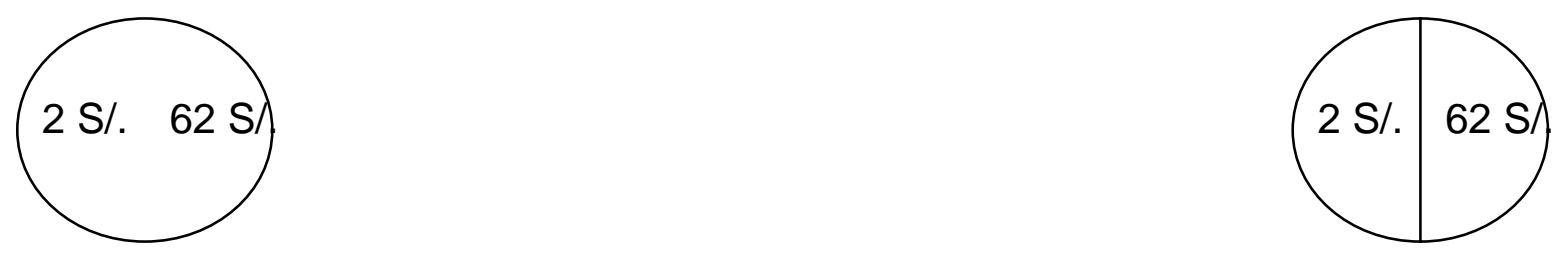

Precio S/0.50 
Figure 4: Binary Choices to Reveal Preferences for Dominated Alternatives
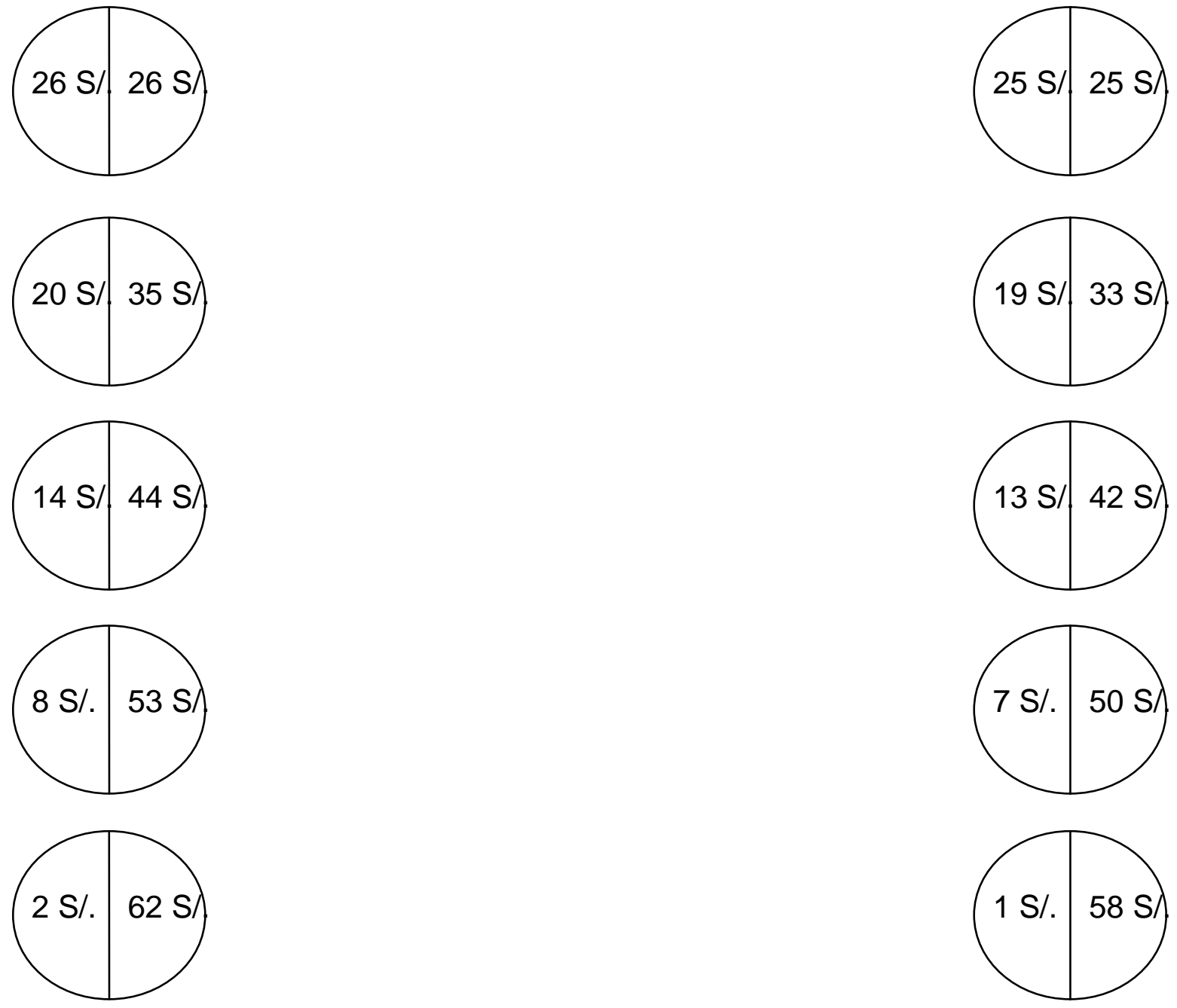
Figure 5: Risk Preference

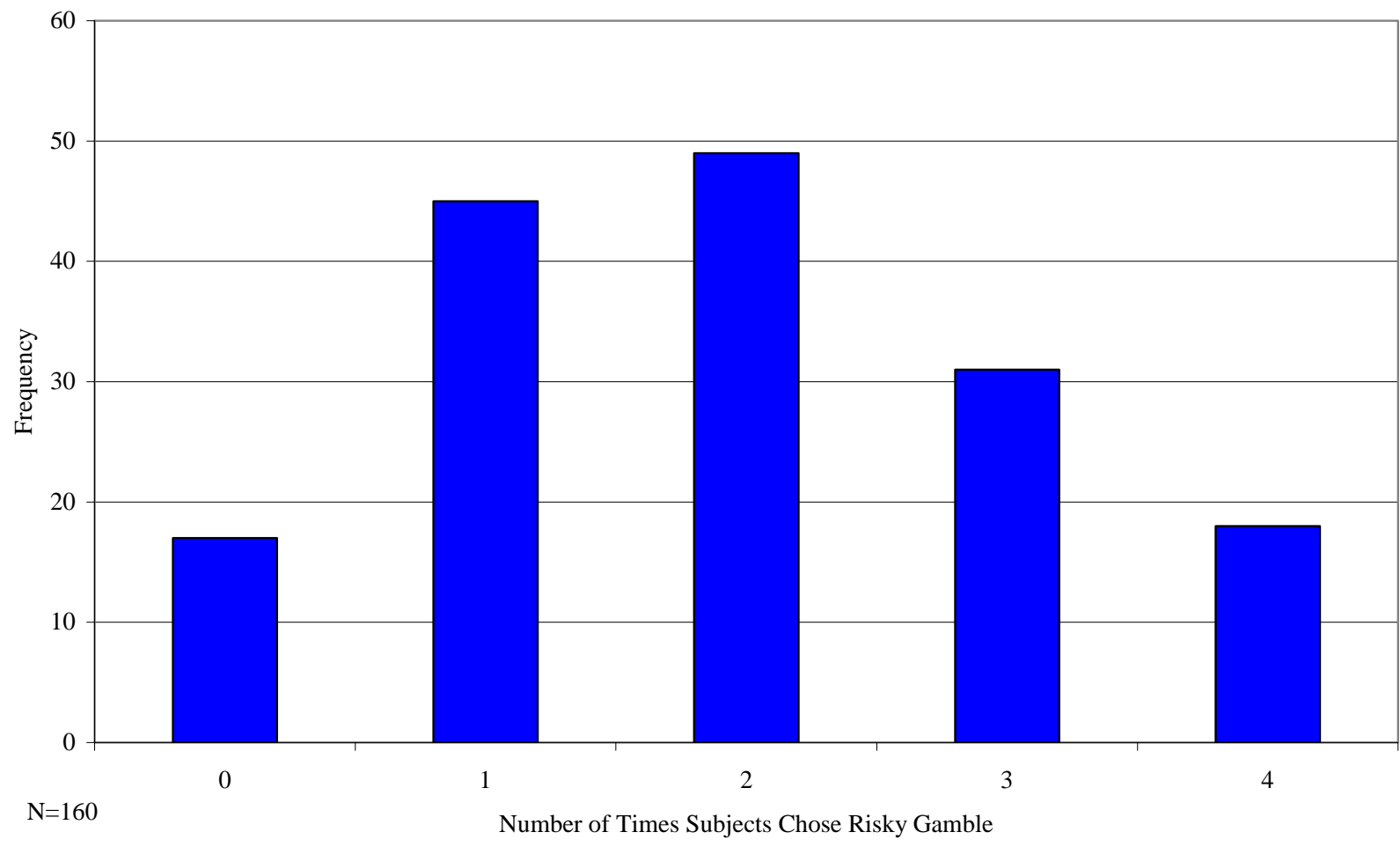

Figure 6: Ambiguity Aversion

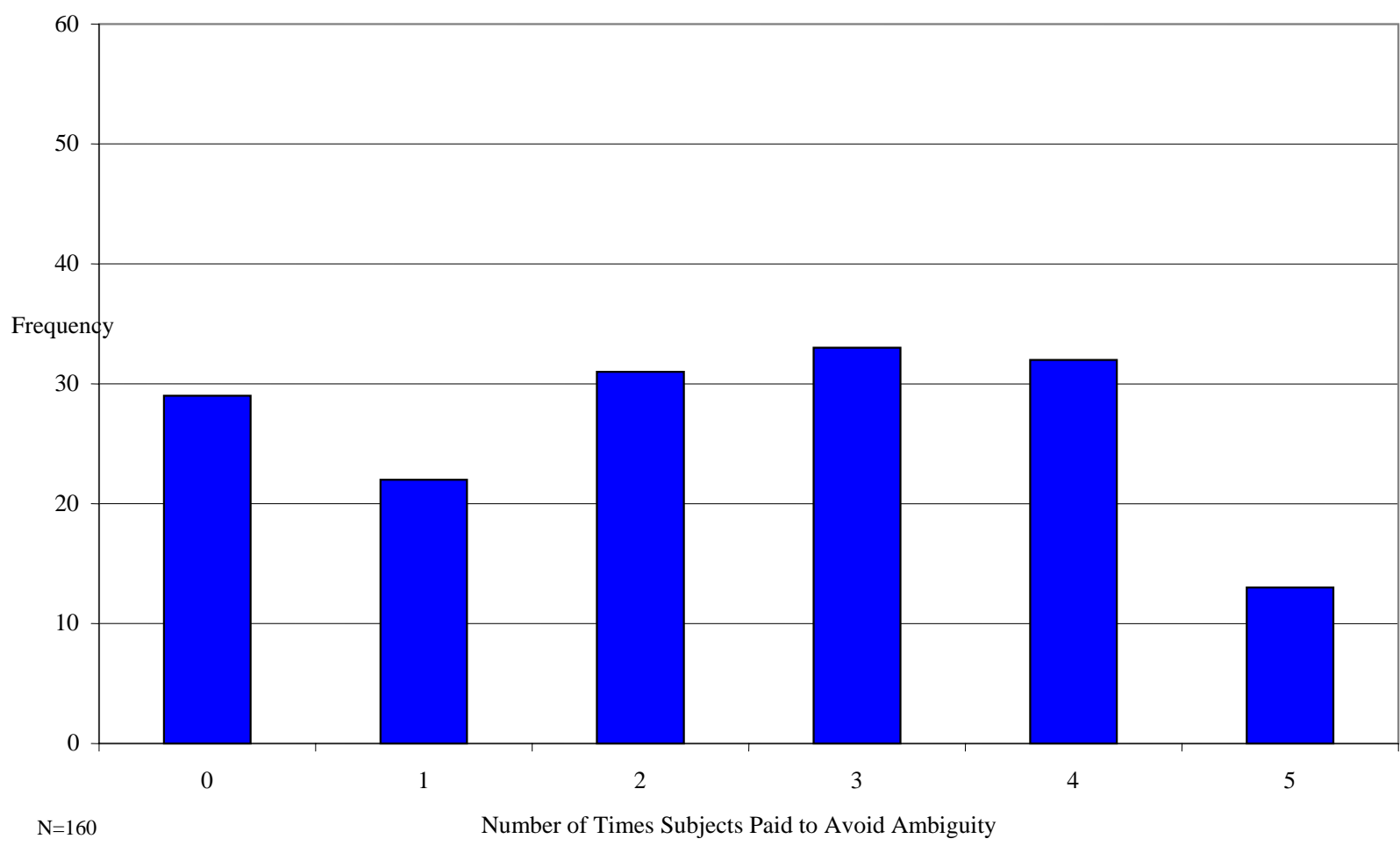


Figure 7: Dominance Preference

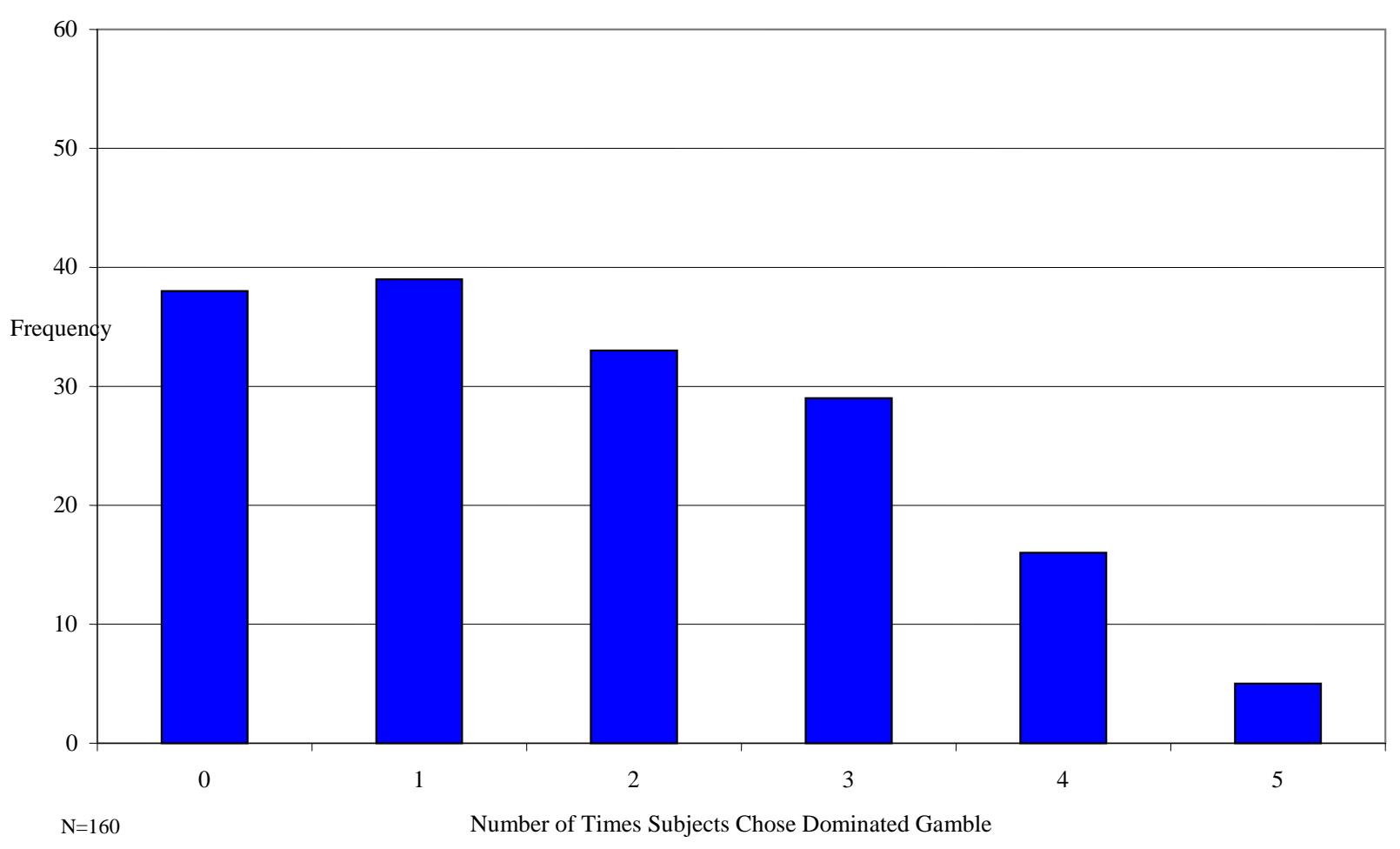

